\title{
It Is a Pleasure to Announce the Issue Titled "Master Class 2021" in Annals of Coloproctology
}

\author{
In Ja Park \\ Editor-in-Chief
}

In this issue, I collate articles from the "masters" of surgical treatment of colorectal disease.

Special issue "Master Class 2021" includes treatment strategies for colorectal disease adopted by surgeons who have greatly influenced many young surgeons.

I would like to thank Jin Cheon Kim, Jun-Gi Kim, Nam Kyu Kim, Seon Hahn Kim, Young Jin Kim, and Jae Hwan Oh for sharing their experience, knowledge, and insights in the field of surgical management of colorectal disease. I am especially grateful to Sir Walter Bodmer, a leading geneticist worldwide, for participating in this issue. He has made major contributions to cancer genetics and was one of the firsts to suggest the human genome project. He, along with his colleague Ellen Solomon, helped locate the APC gene in the 1980s.

In "Genotypic and phenotypic characteristics of hereditary colorectal cancer" [1], Jin Cheon Kim and Walter F. Bodmer provide an overview of hereditary colorectal cancer. In particular, they emphasize variants and newly identified familial colorectal cancer syndrome as well as comment on the clinical utility of multi-gene panel tests.

Jun-Gi Kim, a leading surgeon in the field of laparoscopic colorectal surgery, provides an in-depth review of laparoscopic complete mesocolic excision of right hemicolectomy and shares a perspective on the evolution of cancer surgery [2].

Nam Kyu Kim contributed significantly to the development of rectal cancer surgery worldwide. In "Surgical treatment of low-lying rectal cancer: updates" [3], he introduces the current surgical treatment options and recent oncologic and functional outcomes in low-lying rectal cancer. He also presents challenging surgical cases and discusses individualized treatment approaches. This will help readers practically understand the complexity of low-lying rectal cancer treatment.

In "Robotic intersphincteric resection for low rectal cancer: technical controversies and a systematic review on the perioperative, oncological, and functional outcomes" [4], Seon Hahn Kim presents technical details of robotic intersphincteric resection and functional and oncologic outcomes of robotic intersphecteric resection for managing low rectal cancer. Seon Hahn Kim is a pioneer in minimally invasive surgery for colorectal cancer. He provides wise, practical, and advanced viewpoints for this extreme form of sphincter-preserving resection via a robotic approach.

In "Treatment for peritoneal metastasis of patients with colorectal cancer" [5], Young Jin Kim handled difficult to treat metastasis of colorectal cancer, peritoneal metastasis. He has devoted his career to managing difficult colorectal cancer patients. Peritoneal metastasis is rare and difficult to treat. He provides an overview of recent insights into the management of peritoneal metastasis of colorectal cancer.

Jae Hwan Oh is a very insightful surgeon and researcher. He has extensively focused on the lateral lymph node in rectal cancer owing to the recent interest in lateral pelvic lymph node treatment in the era of neoadjuvant chemoradiotherapy. He shared his experience and insight regarding the role of lateral lymph node dissection in "Lateral pelvic lymph node dissection after neoadjuvant chemoradiotherapy in patients with rectal cancer: a single-center experience and literature review" [6].

I am indebted to Chang Hyun Kim, Sung Ook Bae, Eung Jung Kim, and Gyung Mo Son for helping produce this great issue and their astute and pertinent comments. I would also like to thank the editorial office, manuscript editor, publisher, for their tremendous support in the timely publishing of this issue.

I also wish to acknowledge the contributions and hard work of the dedicated members of our editorial board. I believe this issue will attract and provide valuable insights to the readers of Annals of Coloproctology.

In Ja Park, Editor-in-Chief Kotaro Maeda, Co-Chief-Editor

\section{REFERENCES}

1. Kim JC, Bodmer WF. Genotypic and phenotypic characteristics of hereditary colorectal cancer. Ann Coloproctol 2021;37:368-81.

2. Son GM, Lee IY, Lee YS, Kye BH, Cho HM, Jang JH, et al. Is laparoscopic complete mesocolic excision and central vascular ligation really necessary for all patients with right-sided colon cancer? Ann Coloproctol 2021;37:434-44.

3. Varela C, Kim NK. Surgical treatment of low-lying rectal cancer: updates. Ann Coloproctol 2021;37:395-424. 


\section{Coloproctology in Ja Park}

4. Piozzi GN, Kim SH. Robotic intersphincteric resection for low rectal cancer: technical controversies and a systematic review on the perioperative, oncological, and functional outcomes. Ann Coloproctol 2021;37:351-67.

5. Kim YJ, Kim CH. Treatment for peritoneal metastasis of patients with colorectal cancer. Ann Coloproctol 2021;37:425-33.

6. Kim MC, Oh JH. Lateral pelvic lymph node dissection after neoadjuvant chemoradiotherapy in patients with rectal cancer: a single-center experience and literature review. Ann Coloproctol 2021;37:382-94. 